\title{
Stress-strain behaviour of hybrid-fibre engineered cementitious composite in compression
}

\author{
Zhenbo Wang \\ School of Mechanics and Civil Engineering, China University of Mining \\ and Technology, Beijing, P. R. China (corresponding author: \\ wangzb@cumtb.edu.cn) \\ Jianping Zuo \\ School of Mechanics and Civil Engineering, China University of Mining and \\ Technology, Beijing, P. R. China (corresponding author: zjp@cumtb.edu.cn)

\section{Xiaoyan Zhang} \\ School of Mechanics and Civil Engineering, China University of Mining and \\ Technology, Beijing, P. R. China
}

\author{
Guanghui Jiang \\ School of Mechanics and Civil Engineering, China University of Mining \\ and Technology, Beijing, P. R. China \\ Lulu Feng \\ School of Mechanics and Civil Engineering, China University of Mining \\ and Technology, Beijing, P. R. China
}

Targeting the balance between high strength and toughness of engineered cementitious composite (ECC), polyvinyl alcohol (PVA)-steel hybrid-fibre-reinforced engineered cementitious composites were developed in this study. Cylindrical specimens were tested under uniaxial compression to investigate the stress-strain behaviour of hybrid-fibre composites with particular focus on the impact of matrix strength and steel fibre content. The experimental results indicated that the mechanical properties of hybrid-fibre systems were improved with increasing content of steel fibre, and this enhancement became more and more pronounced with increasing matrix strength. The impact of additional steel fibre on compressive parameters, such as compressive strength, strain corresponding to peak stress, elastic modulus and toughness index, were also strongly influenced by the matrix strength. Positive responses due to steel fibre were reduced with decreasing matrix strength, and even transformed into a negative effect in a low-strength matrix. When considering both high strength and toughness, a moderate amount of steel fibres was favourable. Furthermore, a simple analytical model especially for hybrid-fibre-reinforced ECC was proposed to give satisfactory predictions of the complete stress-strain behaviour. It is expected that this model can be used as a first approximation for non-linear analysis of ECC structures.

$\begin{array}{ll}\text { Notation } \\ A, B & \text { constants } \\ E_{0} & \text { elastic modulus } \\ f_{\mathrm{c}} & \text { uniaxial compressive strength } \\ \alpha & \text { material parameter } \\ \varepsilon & \text { strain } \\ \varepsilon_{0} & \text { strain corresponding to compressive strength } \\ v_{0} & \text { Poisson ratio } \\ \sigma & \text { stress } \\ \sigma_{\mathrm{p}} & \text { proportional limit stress }\end{array}$

\section{Introduction}

Concrete is widely used in civil engineering. However, it has the disadvantage of low tensile strength, brittleness and strain-softening behaviour. In concrete infrastructure, cracks induced by environmental and/or mechanical loads will open quickly to a macroscopically visible level, and when cracks join this can yield even larger cracks. The formation of widely opened cracks accelerates deterioration by providing easy access for aggressive media (e.g. deicing salt) to enter the interior of the structure. Therefore, crack width control has been a concern in the study of the durability of concrete structures.
In recent years, a new class of ultra-high-performance fibrereinforced cementitious composite, called engineered cementitious composite (ECC) and characterised by strain-hardening behaviour accompanied by fine multiple cracks up to the ultimate tensile strain, has been developed ( $\mathrm{Li}, 1993,2002)$. The tensile ductility of ECC, resulting from the formation of numerous steady-state cracks, is several hundred times that of conventional concrete. More importantly, the crack width of each individual crack first increases steadily up to about $100 \mu \mathrm{m}$ and then stabilises until the peak stress is achieved ( $\mathrm{Li}, 1993)$. The tight crack width of ECC has a negligible effect on the permeability process, thus leading to an extended service life of the concrete ( $\mathrm{Li}$ et al., 1995). However, for the purposes of fracture toughness control and fibre dispersion, only a small amount of fine sand is allowed to be included in ECC (Li, 1993; Li et al., 1995). Exclusion of coarse aggregates and a higher cement content in ECC will develop large drying shrinkage during its setting and hardening process. Typically, the ultimate drying shrinkage strain of ECC is approximately three times that of normal concrete (Yang et al., 2007). Such a large shrinkage strain will lead to severe cracking of structures in early age, leading to problems of insufficient durability. To overcome this inherent disadvantage, ECC with characteristics of low drying shrinkage (LSECC) has been developed and applied to jointless concrete pavement 
(Zhang et al., 2009a, 2009b, 2013). The underlying mechanism for low shrinkage is that the composite cement used exhibits an expansive property during hardening and the shrinkage of the composite can be effectively compensated for then.

During recent decades, the mechanical properties of monofibre ECC, such as polyvinyl alcohol (PVA) fibre or polyethylene (PE) fibre-reinforced systems, have been extensively investigated (Li, 2002; Yang et al., 2007; Zhang et al., 2009a, $2009 \mathrm{~b}, 2013)$. It is generally agreed that fibre-reinforced cementitious composite with high-modulus fibre shows high strength but low strain capacity, such as when using steel and carbon fibres, whereas those containing relatively low-modulus fibres, such as PVA and PE fibres, are quite the opposite (Li et al., 1996; Maalej et al., 2005; Maalej et al., 2012; Park et al., 2012). Meanwhile, the gradual and multi-scale nature of fracture in cementitious composites necessitates that a given fibre can provide reinforcement only within a limited range of strains (Banthia et al., 2014). In practice, both sufficient strain capacity and adequate ultimate strength are expected in ECC structures. A high strain capacity achieved by multiple fine cracks is important for the energy absorption and long-term durability of structures, while high strength may delay crack initiation and facilitate the design of size-efficient structural members. To obtain the optimal properties, blending different types of fibres that vary in terms of constitutive response or size into the ECC matrix could be a solution. It is expected that fibres with low modulus are more effective for increasing ductility, whereas fibres with high modulus are more effective for enhancing strength. Thus, the target balance between strain capacity and ultimate strength of the material can be achieved in order to better meet the material performance requirements of practical applications. In a previous study, the tensile performance of hybrid-fibre-reinforced ECC was comprehensively investigated, and a satisfactory balance between tensile strength and ductility was obtained (Wang et al., 2015). However, there still exists little information on the stress-strain behaviour in compression of such hybrid-fibre-reinforced ECC, which is essential for the design and analysis of ECC structural members.

The approach selected in this research is to blend PVA and steel fibres in an LSECC matrix to enhance both the strength (compressive strength) and strain capacity (compressive toughness) of the material. This is accomplished by mixing PVA fibres of a fixed volume fraction with steel fibres of four different volume fractions, respectively. The stress-strain behaviour of PVA-steel hybrid-fibre LSECC in uniaxial compression is experimentally evaluated with a particular focus on the effect of water-to-binder ratio. After that, the effect of parameters such as volume fraction of additional steel fibres and water-to-binder ratio on the strength, elastic modulus, strain corresponding to peak stress and Poisson ratio are presented and discussed. Based on the experimental results, a simple analytical model is proposed to predict the complete stress-strain characteristics of hybrid-fibre
LSECC under uniaxial compression, which is expected to be used for non-linear analysis of ECC structures.

\section{Experimental programme}

This experimental programme is designed to investigate the effect of additional steel fibre on the compressive behaviour of traditional mono PVA fibre-reinforced LSECC with different matrix strength. Thus, three water-to-binder ratios were used to fabricate matrixes with different strengths. For each matrix type, the volume fraction of PVA fibre was kept constant while the volume fractions of the additional steel fibres varied. The compressive behaviours including stress-strain relations, elastic modulus, Poisson ratio, proportional limit, strength, strain at peak stress and toughness were then assessed. In addition, analytical modelling of the stress-strain behaviour of hybrid-fibre-reinforced LSECC was conducted and compared with the experimental results.

\section{Materials}

A newly developed composite cement with the characteristic of low drying shrinkage (Zhang et al., 2009a, 2009b) and silica sand with an average particle size of $0 \cdot 10 \mathrm{~mm}$ were used to prepare the matrixes. The detailed chemical content of the composite cement can be found elsewhere (Wang et al., 2015). To examine the effect of water-to-binder ratio on the compressive properties, three different water-to-binder ratios of $0 \cdot 25,0.35$ and 0.55 were selected in the mix design to prepare matrixes with different strengths, which were designated M1-0, M2-0 and M3-0, respectively. The mixture proportions of these three matrixes are listed in Table 1. A commercial polycarboxylate superplasticiser was utilised to adjust the workability of the fresh paste. PVA fibre provided by Kuraray Company in Japan and steel fibre provided by Changhong Company in China were employed as reinforcement for the fibre-containing mixtures. Table 2 shows the physical properties of the PVA and steel fibres. In the mix design, the volume fraction of PVA fibres was maintained as $1.7 \%$, which is commonly adopted in ECC mixtures, while the volume fractions of steel fibres varied at $0 \cdot 0,0 \cdot 6$, 1.0 and $1.5 \%$. Thus, four test series were formed for each matrix type as summarised in Table 3; these were designated as Mono, Hy1, Hy2 and Hy3, respectively, according to the content of additional steel fibres. For example, the M2 mixture containing $1 \cdot 7 \%$ PVA fibre and $1 \cdot 0 \%$ steel fibre was designated as M2-Hy2.

\section{Specimens, curing and test methods}

A vertical type mortar mixer of 1.51 capacity was used to mix the constituent materials. The composite cement and silica sand

Table 1. Mix proportions of three different types of matrixes

\begin{tabular}{|lcccc|}
\hline Mix no. Composite cement & Water $^{\mathbf{a}}$ & Sand $^{\mathbf{a}}$ & Superplasticiser $^{\mathbf{a}}$ \\
\hline M1 & 1.0 & 0.25 & 0.2 & 0.0150 \\
M2 & 1.0 & 0.35 & 0.3 & 0.0075 \\
M3 & 1.0 & 0.55 & 0.8 & 0 \\
\hline
\end{tabular}

${ }^{a}$ All numbers are given in mass ratios to composite cement 
Table 2. Physical properties of PVA and steel fibres

\begin{tabular}{|lccccc|} 
& Density: $\mathbf{g} / \mathbf{c m}^{\mathbf{3}}$ & Tensile strength: MPa & Elastic modulus: GPa & Diameter: $\mathbf{m m}$ & Length: $\mathbf{m m}$ \\
\hline PVA fibre & 1.2 & 1620 & $42 \cdot 8$ & 0.039 & 12 \\
Steel fibre & 7.8 & 2750 & 210 & $0 \cdot 200$ & 13
\end{tabular}

Table 3. Test series for each matrix type

\begin{tabular}{|lcc|} 
Mix name & PVA fibre in volume: $\%$ & Steel fibre in volume: \% \\
\hline Mono & $1 \cdot 7$ & 0.0 \\
Hy1 & 1.7 & 0.6 \\
Hy2 & $1 \cdot 7$ & 1.0 \\
Hy3 & 1.7 & 1.5 \\
\hline
\end{tabular}

were first dry-mixed for about $1 \mathrm{~min}$ at low speed. Then water pre-mixed with superplasticiser was slowly added into the dry components. Wet mixing was continued for 3-5 min until a uniform flowable paste was achieved. During this period, the bottom of the mixing bowl had to be scraped manually to ensure that no solid materials stuck to the bottom. The fibres were then gradually dispersed into the mixer by hand and the speed of the mixer was subsequently increased to ensure a uniform distribution with no fibre bundles. After that, the fresh mixture was carefully cast into polyvinyl chloride (PVC) moulds in two equal layers, with each layer being vibrated for about $1 \mathrm{~min}$. After smoothing the surface, the specimens were covered with plastic sheets for $24 \mathrm{~h}$ to prevent moisture loss. Then they were demoulded and cured in a standard curing room at a temperature of $20 \pm 2^{\circ} \mathrm{C}$ and relative humidity of more than $95 \%$ until the age of $28 \mathrm{~d}$.

Uniaxial compressive tests were carried out to obtain the complete compressive stress-strain relations and other related mechanical parameters, such as compressive strength and strain of hybrid-fibre-reinforced ECCs. A set of three cylinder specimens with dimensions of $\varnothing 50 \times 100 \mathrm{~mm}$ were prepared for each mixture. Prior to testing, both the top and bottom faces of each cylinder specimen were carefully polished to ensure parallel loading. For all compressive tests, a servohydraulic testing machine with a $1000 \mathrm{kN}$ capacity was used. Figure 1 shows the detailed experimental set-up for the test. The actuator strain rate used for controlling the test was $2 \times 10^{-4} / \mathrm{min}$, which was measured by a displacement fixture containing two linear variable differential transducers (LVDTs) mounted on the surface of the specimen. The stress and strain were recorded using a data acquisition system connected to the control system, see Figure 1. The uniaxial compressive behaviour can then be determined.

\section{Results and discussion}

Stress-strain curves under uniaxial compression

Figures 2, 3 and 4 display all of the compressive stress-strain diagrams of mono and hybrid-fibre-reinforced composites with

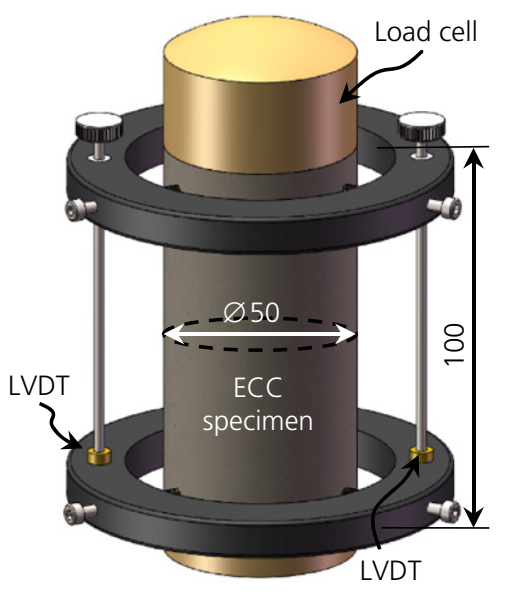

Figure 1. Experimental set-up for uniaxial compression

matrix strength varying from high to low (M1, M2, M3) at the age of $28 \mathrm{~d}$, respectively. As a reference, the stress-strain curves of each matrix are provided as well (dashed lines). As the figures show, all of the stress-strain curves can be divided into two stages - namely, an ascending stage up to the peak stress and a subsequent descending stage. In the ascending stage, the stress-strain curves first behave elastically up to the end of the initial linear segment, after which the curves deviate from linear behaviour and behave non-linearly up to the peak stress $f_{\mathrm{c}}$ - that is, compressive strength. The stress at the end of the linear segment is termed the proportional limit stress $\sigma_{\mathrm{p}}$, then the proportional limit $\sigma_{\mathrm{p}} / f_{\mathrm{c}}$ is defined as the ratio of proportional limit stress to peak stress. The proportional limits of both non-fibre-containing mixtures and fibre-reinforced mixtures are determined and listed in Table 4 . It can be seen that all the fibre-containing mixtures show higher proportional limits compared to non-fibre-containing mixtures with identical water-to-binder ratio. This is attributed to the bridging effect of fibres to internal micro cracks during the loading process, which might extend the elastic stage of the material. The proportional limits of fibre-reinforced mixtures range within $0 \cdot 33$ to $0 \cdot 40$, with an average value of $0 \cdot 35$ and a standard deviation of $0 \cdot 022$. Such a range is similar to that of conventional concrete, which commonly lies between 0.30 and $0 \cdot 50$. When the descending stage is concerned, all the matrixes fall suddenly after the peak point, showing obvious brittle failure. However, the fibre-reinforced mixtures drop slowly with increasing strain after the maximum stress due to the confinement effect by fibre bridging. Depending on the matrix strength and volume fraction of additional steel fibres, different 


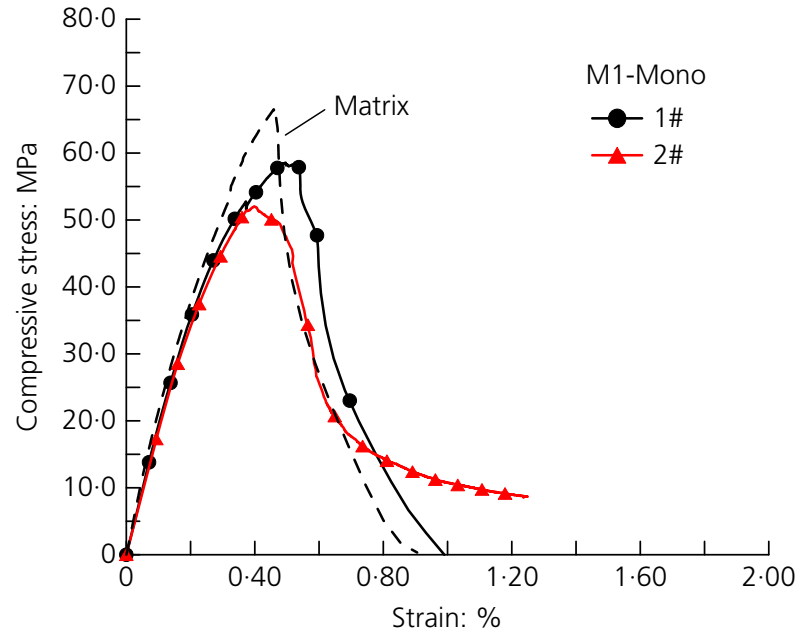

(a)

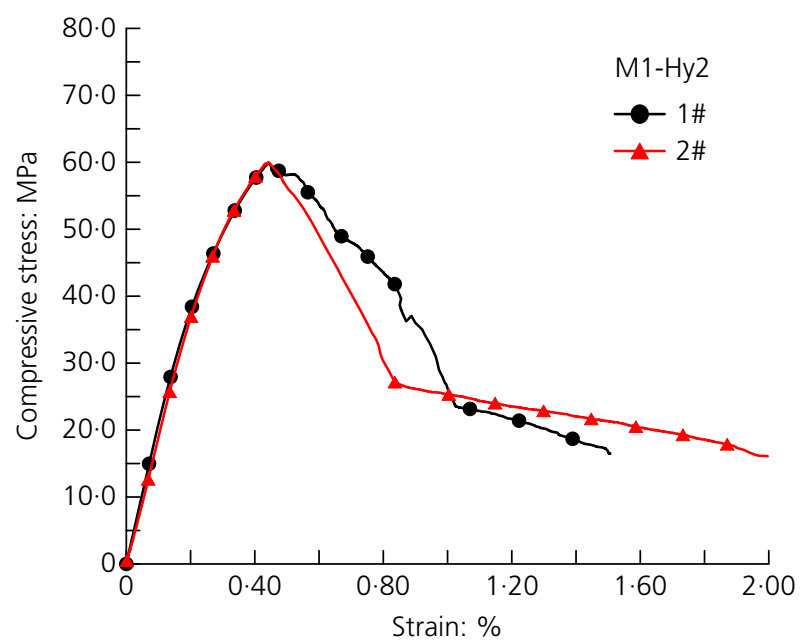

(c)

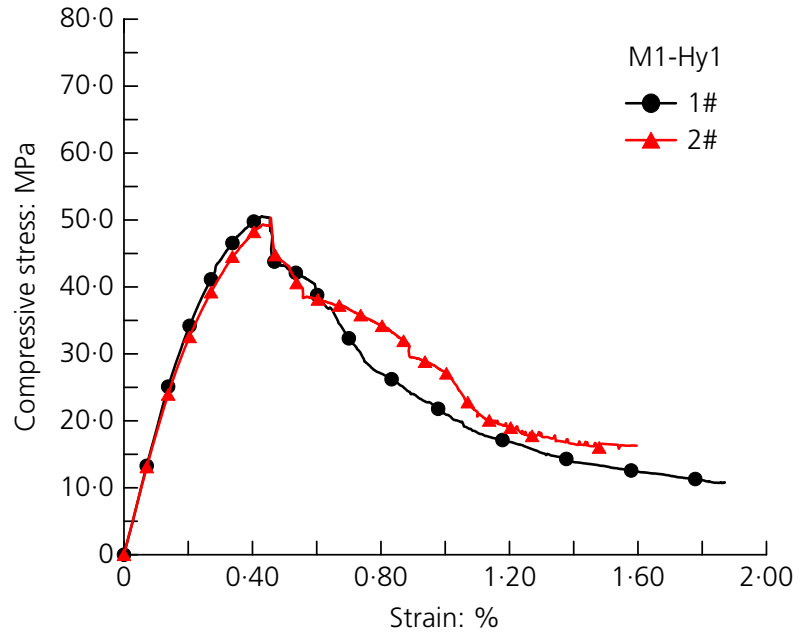

(b)

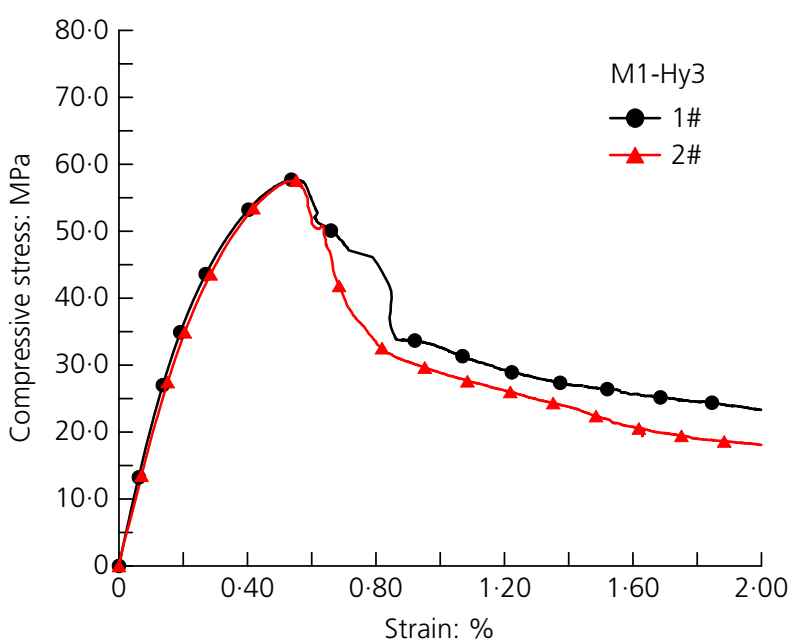

(d)

Figure 2. Stress-strain curves of M1 with different steel fibre additions: (a) PVA1.7\%; (b) PVA1.7\%STO.6\%; (c) PVA 1.7\%ST1.0\%; (d) PVA $1.7 \%$ ST1.5\% under uniaxial compression

post-peak behaviours are obtained. As the matrix strength decreases, the descending stage of fibre-reinforced mixtures tend to level off to an approximately constant value, implying that matrix strength may play an important role in post-peak strain capacity.

In order to analyse the effect of steel fibre addition on the compressive properties, a comparison of typical compressive stress-strain behaviours of M1, M2 and M3 with different steel fibre content are presented, respectively, in Figures 5(a), 5(b) and $5(\mathrm{c})$. As can be seen, with the increase of steel fibre content, high-strength mixtures (M1-) show a clear improvement in stress-strain behaviour. The ascending slope increases slightly with steel fibre addition, while the descending stage gains a significant promotion, yielding higher residual stress. Apparently, improvement in both the pre-peak stage and the post-peak stage will result in a larger envelope area under the stress-strain curves, which indicates that better energy absorption capacity can be achieved by incorporating additional steel fibres into high-strength mixtures. These positive responses of additional steel fibre appear to be depressed with the increase of water-to-binder ratio. When it comes to low-strength mixtures (M3-), there are no obvious differences in stress-strain relations between the mixtures containing different volume fractions of steel fibre. This is likely to be due to the difference in bonding strength dependency between steel and PVA fibres. The influence of water-to-binder ratio on bonding strength between steel fibre and matrix is more noticeable than in the case of PVA fibre. Increasing the water-to-binder ratio will result in much weaker bonding strength of the steel fibre/matrix. Therefore, the enhancement effect of steel fibre tends to be eliminated in such a low-strength matrix. In other words, steel fibre may be more suitable to be used in a composite with a high-strength matrix. 


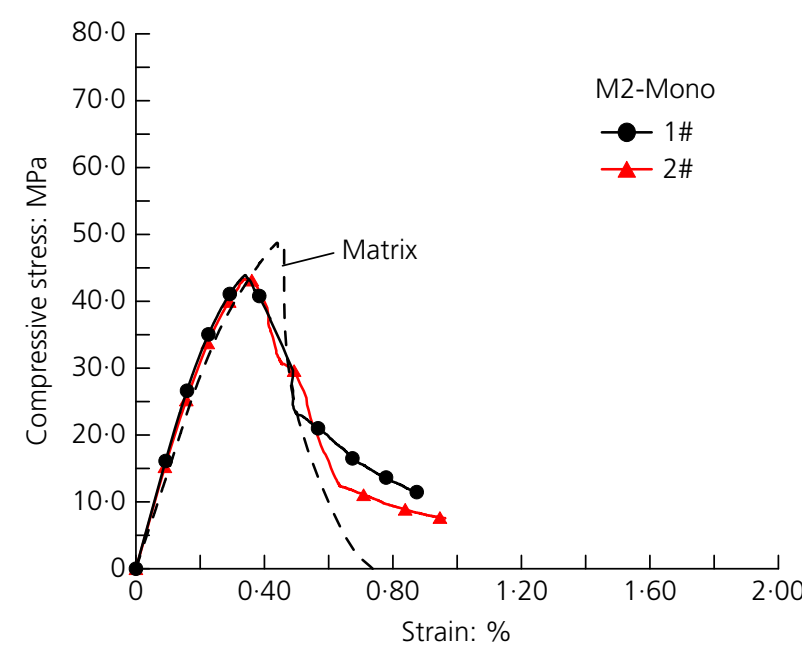

(a)

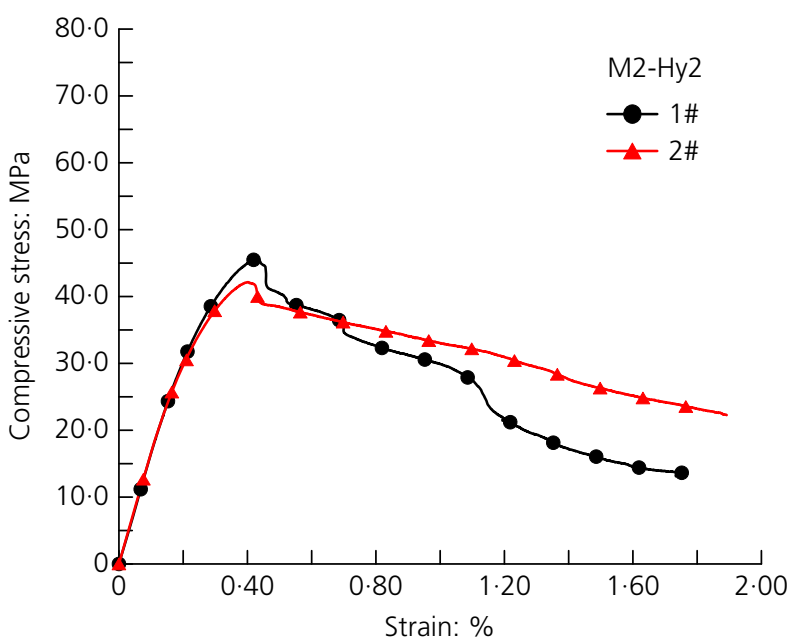

(c)

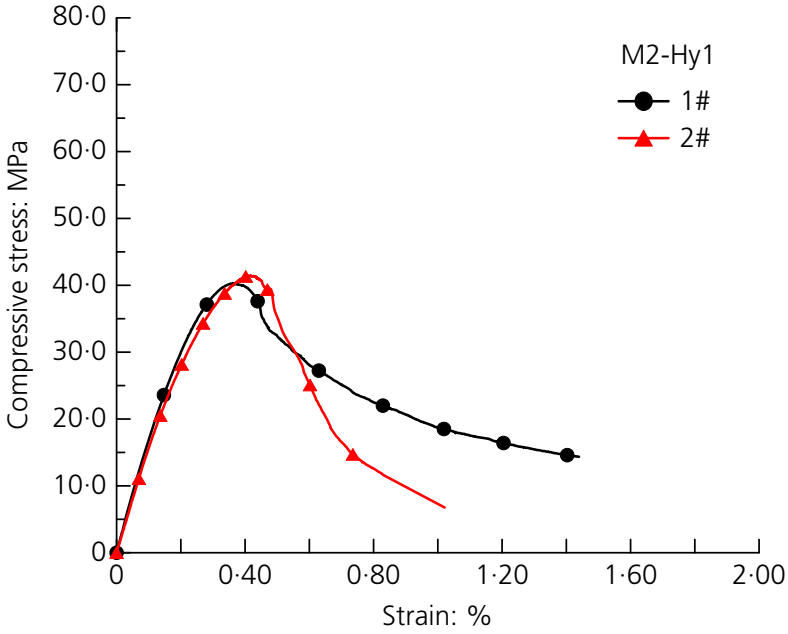

(b)

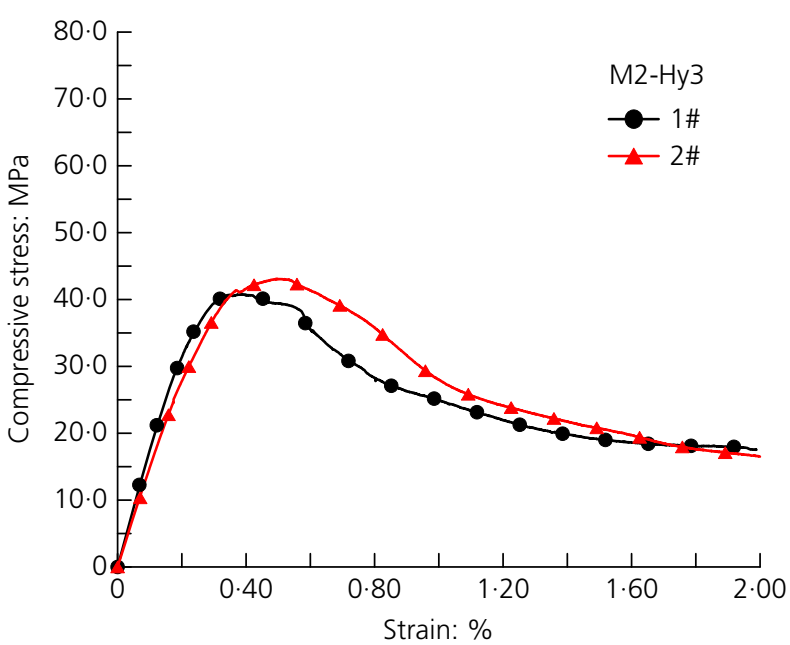

(d)

Figure 3. Stress-strain curves of M2 with different steel fibre additions: (a) PVA1.7\%; (b) PVA1.7\%ST0.6\%; (c) PVA1.7\%ST1.0\%; (d) PVA $1.7 \%$ ST $1.5 \%$ under uniaxial compression

\section{Compressive parameters}

Based on the stress-strain curves, compressive parameters such as the compressive strength $f_{\mathrm{c}}$, peak strain $\varepsilon_{0}$, elastic modulus $E_{0}$, Poisson ratio $v_{0}$ and toughness index of each mixture were determined and these are summarised in Table 4, where each data entry was attained by averaging three test results. Figure 6 illustrates the influence of the addition of steel fibre on each mechanical parameter of fibre-reinforced mixtures with different matrix strength. In this figure, each histogram bar presents an average value from three specimens, and the variability of each test data value is represented by the standard deviation, shown as error bars.

The compressive strength $f_{\mathrm{c}}$ and peak strain $\varepsilon_{0}$ refer to the maximum stress and the corresponding strain in the stressstrain curves, respectively. As displayed in Figure 6(a), three distinct strength grades are formed by adjusting the water-to-binder ratio. For each different strength grade, the impact of the addition of steel fibre on compressive strength varies. In the case of the high-strength matrix (M1-), increasing the volume fraction of steel fibres leads to a noticeable increase in the compressive strength. This improvement might be attributed to the increased shear capacity across the cracking section and the improved peak crack bridging stress provided by the steel fibre. However, as the water-to-binder ratio increases, the positive effect of the addition of steel fibre is reduced and finally transformed into a negative effect. For instance, the compressive strengths of the M3 mixture are $15.8 \mathrm{MPa}$, $15 \cdot 1 \mathrm{MPa}, 13.5 \mathrm{MPa}$ and $13 \cdot 5 \mathrm{MPa}$ for the steel fibre dosage of $0,0 \cdot 6,1 \cdot 0$ and $1.5 \%$, respectively. This is understandable because the addition of steel fibre, which is coarser in its dimensions and weaker in its interfacial bonding to the lowstrength matrix than the PVA fibres, may provide less help in terms of increasing the maximum crack bridging stress, or it 


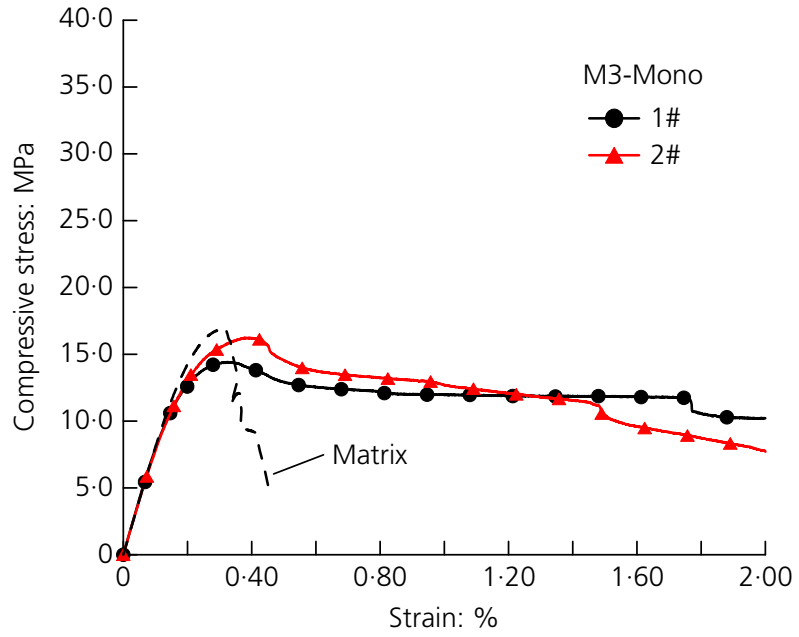

(a)

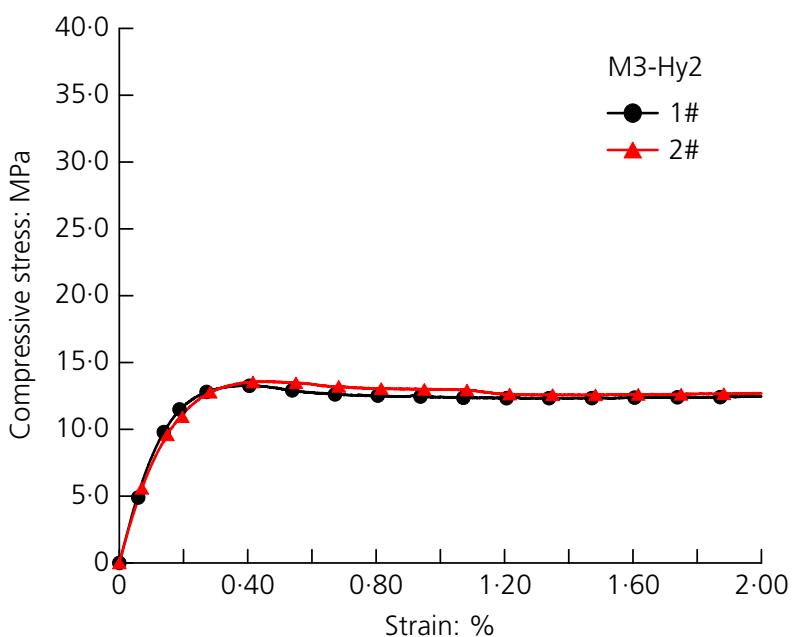

(c)

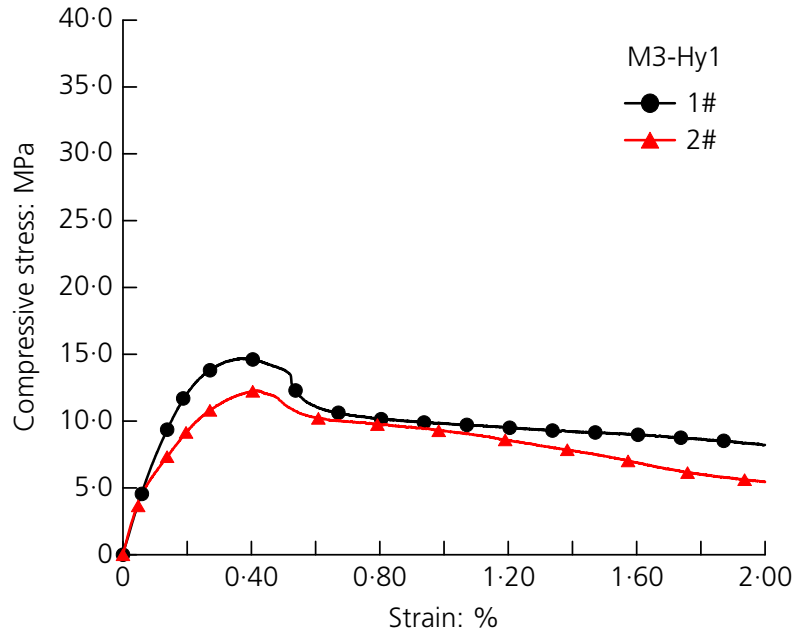

(b)

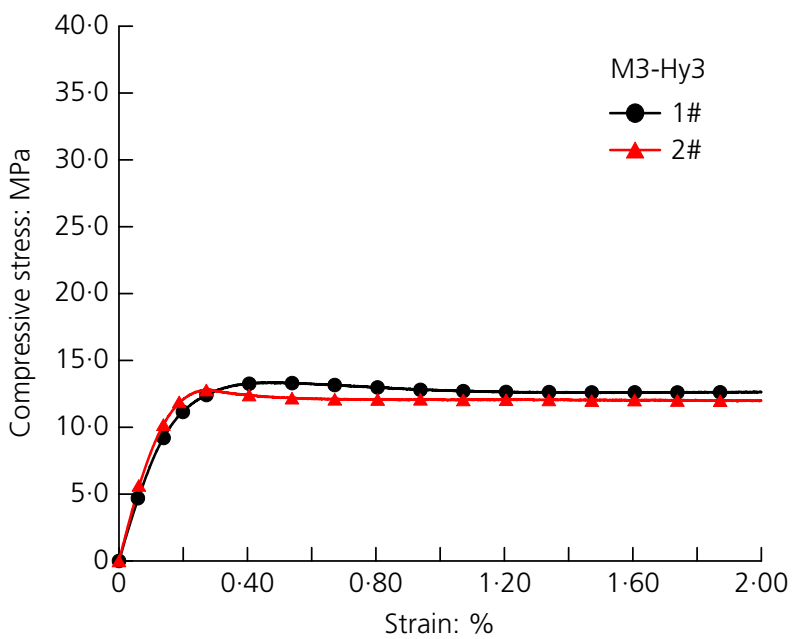

(d)

Figure 4. Stress-strain curves of M3 with different steel fibre additions: (a) PVA1.7\%; (b) PVA1.7\%STO.6\%; (c) PVA $1.7 \%$ ST1.0\%; (d) PVA $1.7 \%$ ST $1.5 \%$ under uniaxial compression

could even play a negative role in the case of a relatively high dosage, which may influence the dispersion of fibres in the matrix.

The peak strains of each mixture are plotted against the volume fraction of steel fibre in Figure 6(b). The results show that the peak strain ranges from 0.33 to $0.55 \%$ with an increase in matrix strength and steel fibre content. Generally, mixtures with a matrix of higher strength show larger peak strain, which is consistent with the case of conventional concrete. The peak strains of high-strength mixtures (M1-) are increased slightly from $0 \cdot 45$ to $0 \cdot 55 \%$ with the increase of steel fibre content from $0 \cdot 0$ up to $1 \cdot 5 \%$. As regards the mixtures with lower matrix strength (M2- and M3-), their peak strains are increased with steel fibre addition when its dosage is less than or equal to $1.0 \%$ (Hy2). When the steel fibre content goes beyond $1 \cdot 0 \%$, the peak strains instead show a decreasing trend.
This means that a moderate amount of steel fibres is needed in lower strength ECC to achieve an improvement in peak strain. Although to some extent, adding steel fibre may delay the coalescence of micro cracks, yielding a larger peak strain, on the other hand, a relatively high content of fibres will affect the distribution of fibres in the matrix. It seems that whether the positive effect of steel fibre on crack bridging or the negative effect on fibre distribution is likely to prevail mainly depends on the matrix strength. In the case of a highstrength matrix, the strong bond strength existing between the fibre/matrix interfaces allows the bridging effect of steel fibres to be activated, even if the fibre dispersion is somewhat impaired.

The elastic modulus is calculated by dividing the stress at the end of the initial linear portion of the stress-strain curve by the corresponding strain. Figure 6(c) shows the elastic modulus 
Table 4. Mechanical parameters of fibre-reinforced ductile composites under uniaxial compression

\begin{tabular}{|c|c|c|c|c|c|c|}
\hline No. & $f_{c}: M P a$ & $\varepsilon_{0}: \%$ & $\sigma_{\mathrm{p}} / f_{\mathrm{c}}$ & $E_{0}: \mathrm{GPa}$ & $v_{0}$ & Toughness index \\
\hline M1-0 & $67 \cdot 0$ & 0.462 & $0 \cdot 21$ & $25 \cdot 3$ & $0 \cdot 199$ & 1.63 \\
\hline M1-Mono & $53 \cdot 3$ & 0.448 & 0.35 & $18 \cdot 7$ & $0 \cdot 165$ & $2 \cdot 07$ \\
\hline M1-Hy1 & $51 \cdot 7$ & 0.456 & 0.34 & $18 \cdot 6$ & $0 \cdot 157$ & $2 \cdot 62$ \\
\hline M1-Hy2 & $59 \cdot 4$ & 0.459 & 0.35 & $21 \cdot 5$ & 0.179 & $2 \cdot 85$ \\
\hline M1-Нy3 & $57 \cdot 7$ & 0.547 & 0.33 & $20 \cdot 7$ & $0 \cdot 181$ & $2 \cdot 69$ \\
\hline M2-0 & $49 \cdot 9$ & 0.438 & 0.27 & $16 \cdot 2$ & $0 \cdot 155$ & $1 \cdot 37$ \\
\hline M2-Mono & $43 \cdot 6$ & 0.339 & 0.35 & $17 \cdot 1$ & $0 \cdot 180$ & $2 \cdot 47$ \\
\hline M2-Hy1 & $40 \cdot 9$ & $0 \cdot 390$ & 0.32 & $16 \cdot 6$ & $0 \cdot 181$ & $2 \cdot 61$ \\
\hline M2-Hy2 & $43 \cdot 1$ & 0.445 & 0.37 & $16 \cdot 6$ & 0.173 & $3 \cdot 32$ \\
\hline M2-Нy3 & $41 \cdot 9$ & 0.440 & 0.37 & $16 \cdot 2$ & $0 \cdot 160$ & $3 \cdot 19$ \\
\hline M3-0 & $15 \cdot 8$ & 0.279 & 0.37 & $9 \cdot 53$ & $0 \cdot 150$ & 1.65 \\
\hline M3-Mono & $15 \cdot 1$ & 0.327 & 0.38 & $8 \cdot 55$ & $0 \cdot 157$ & $3 \cdot 51$ \\
\hline M3-Hy1 & $13 \cdot 5$ & 0.390 & 0.33 & $7 \cdot 58$ & $0 \cdot 148$ & $3 \cdot 20$ \\
\hline M3-Hy2 & $13 \cdot 5$ & 0.395 & 0.36 & $8 \cdot 11$ & $0 \cdot 145$ & $3 \cdot 52$ \\
\hline M3-Hy3 & $13 \cdot 1$ & 0.375 & 0.40 & $8 \cdot 30$ & $0 \cdot 145$ & $3 \cdot 65$ \\
\hline
\end{tabular}

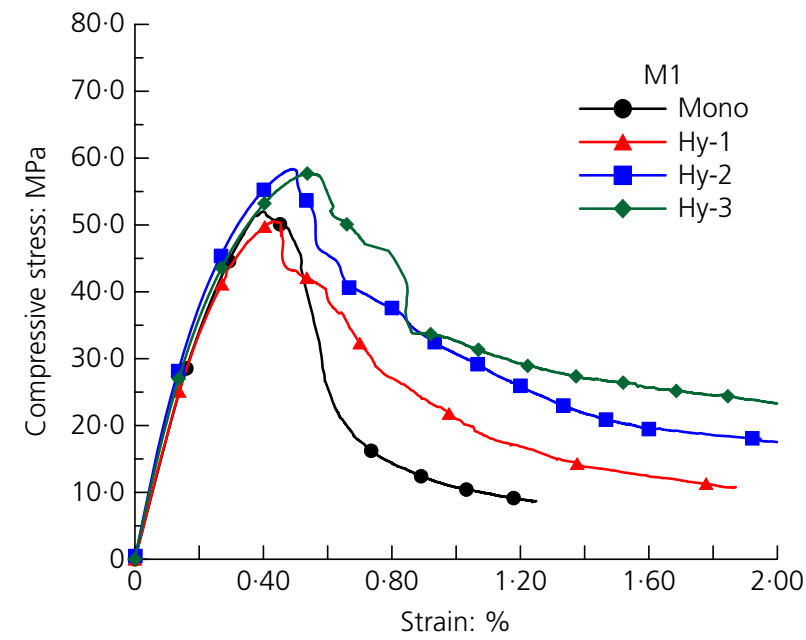

(a)

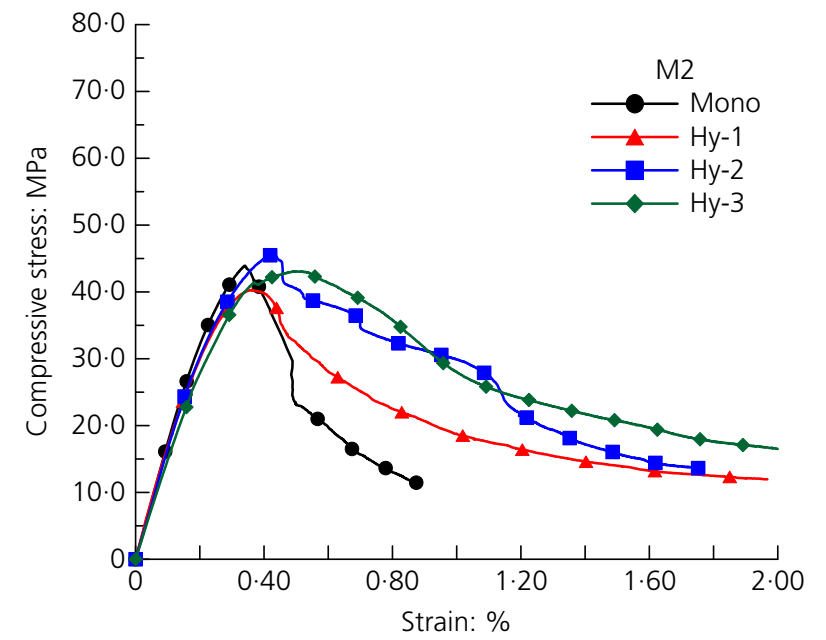

(b)

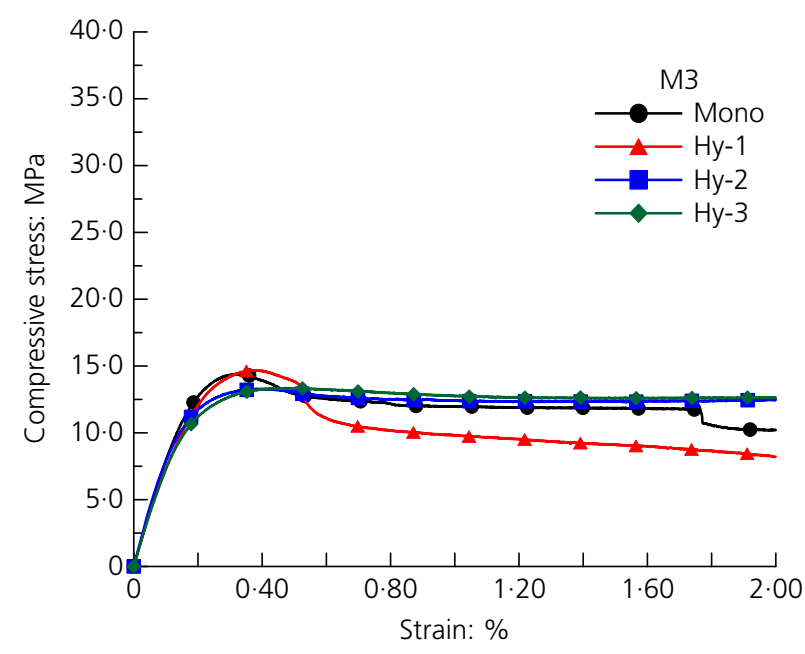

(c)

Figure 5. Comparison of uniaxial compressive stress-strain relations of: (a) M1; (b) M2; (c) M3 with different steel fibre additions 


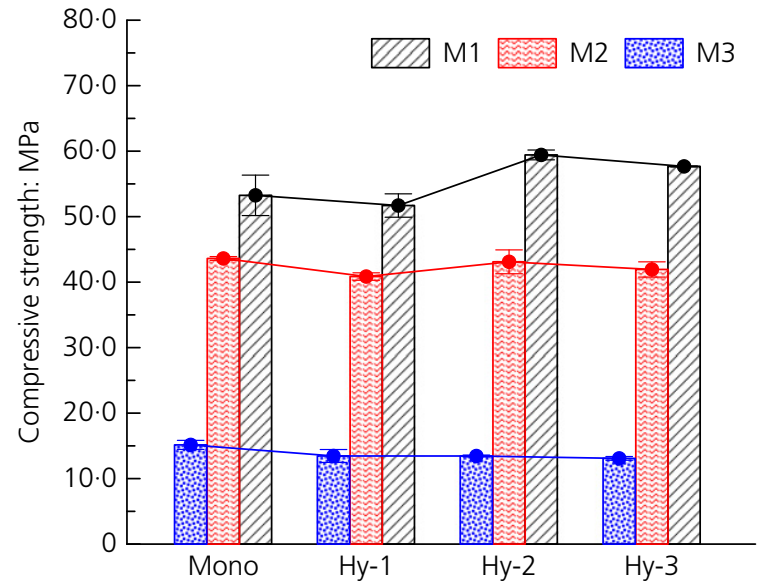

(a)

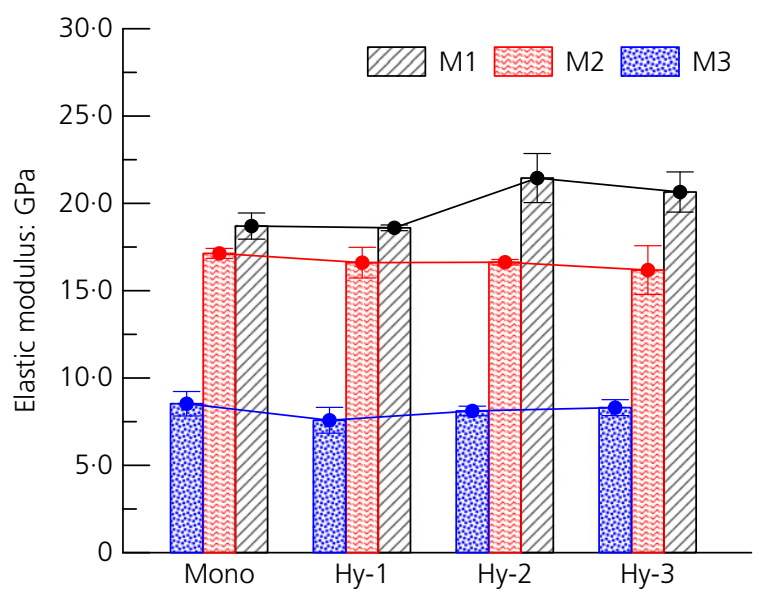

(c)

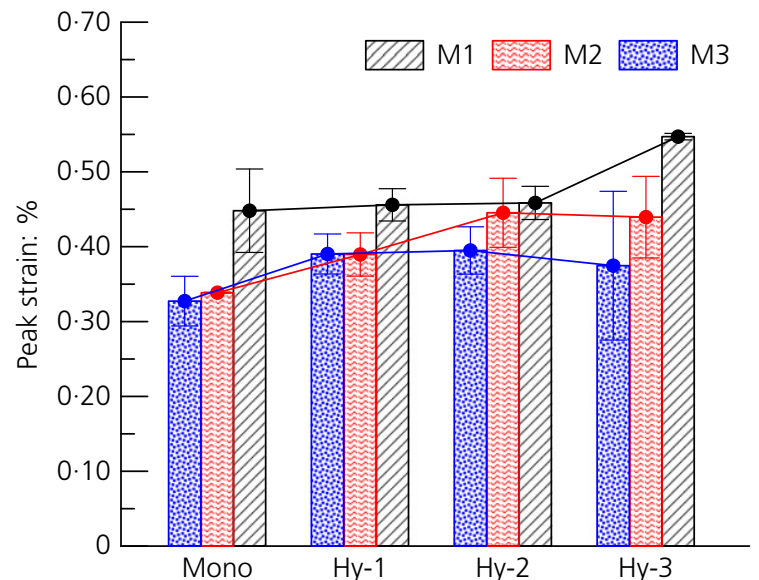

(b)

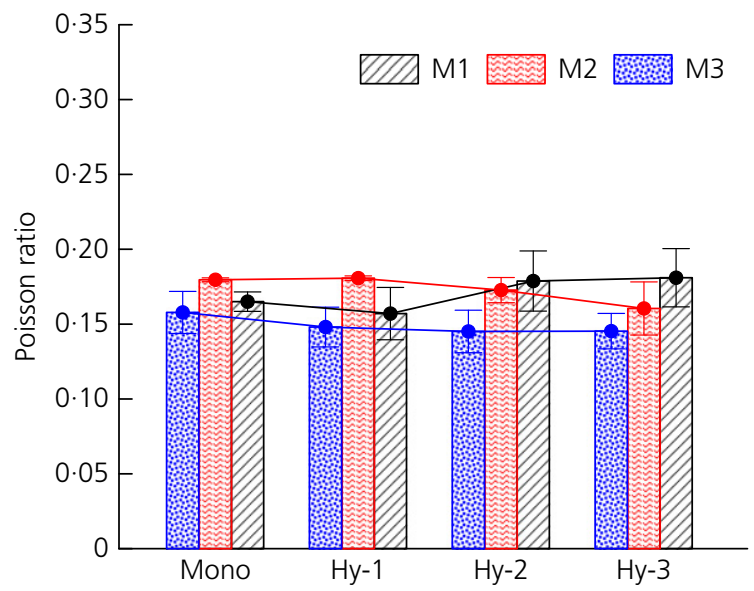

(d)

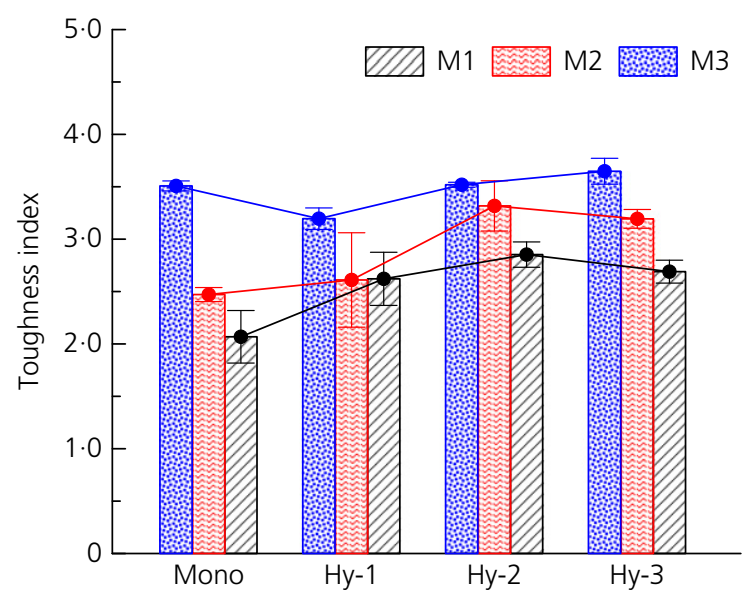

(e)

Figure 6. Effect of steel fibre addition on: (a) compressive strength; (b) peak strain; (c) elastic modulus; (d) Poisson ratio; and (e) toughness index of fibre-containing mixtures

of fibre-containing mixtures as a function of steel fibre dosage. It can be observed that the basic trend of elastic modulus is similar to that of compressive strength. The exclusion of coarse aggregate from the matrix results in a smaller elastic modulus compared to that of conventional concrete. The elastic modulus of the M1, M2 and M3 mixtures ranges within 18.6-21.5 GPa, 16.2-17.1 GPa and 7.6-8.5 GPa, respectively. For mixtures with lower matrix strength (M2- and M3-), 
the elastic modulus shows a slightly decreasing trend as the steel fibre content increases. Although steel fibre itself possesses a much higher elastic modulus than the matrix, increasing amounts of defects or pores might be incorporated by additional steel fibre during the mixing process, and their existence may somewhat reduce the elastic modulus. When it comes to the high-strength mixture (M1-), however, much stronger bonding behaviour will be generated between steel fibre/matrix interfaces, which might compensate for the negative effect of flaws inherent from the mixing process. As a result, a slightly increasing trend is attained for the elastic modulus of the high-strength mixture.

The Poisson ratio is determined by the ratio of radial strains to axial strains at the end of the initial linear portion of the stress-strain curves. From the test data listed in Table 4, Poisson ratios of fibre-containing M1, M2 and M3 mixtures are in the range of $0 \cdot 157-0 \cdot 181,0 \cdot 160-0 \cdot 181$ and $0 \cdot 145-0 \cdot 158$, respectively. As can be seen, for each strength grade, there are no obvious differences in Poisson ratio between hybrid-fibrereinforced mixtures with various steel fibre contents. Thus, for simplification, the value $v_{0}$ of each strength grade can be considered independent of the steel fibre content and their average values are suggested for structural analysis. The derived average $v_{0}$ of fibre-containing M1, M2 and M3 mixtures are $0 \cdot 17,0 \cdot 17$ and $0 \cdot 15$, respectively. A slight decline trend of $v_{0}$ is found with increasing water-to-binder ratio, which is consistent with the findings by Zhou et al. (2015).

Toughness index is a crucial parameter for quantitatively evaluating the strain capacity and/or energy-absorption capacity of a material. Up to now, a widely accepted standard still does not exist for the determination of the compressive toughness index of cementitious composites. Various definitions of toughness index have been proposed to quantify the ductility of fibre-containing cementitious composites under compression. Fanella and Naaman (1985) defined the toughness index as the ratio of the area under the stress-strain curve of a fibrereinforced matrix to that of the unreinforced control matrix. Mansur et al. (1999) defined the toughness index as the ratio of the area under the stress-strain curve up to a strain of $3 \varepsilon_{0}$ to the area up to a strain of $\varepsilon_{0}$. According to Zhou et al. (2015), the toughness index is proposed as the ratio of the post-peak area under the stress-strain curve up to a stress of $0 \cdot 30 f_{\mathrm{c}}$ at the post-peak portion to the pre-peak area up to the peak stress. Considering the extent of the stress-strain curves obtained and the slow decreasing rate of the post-peak stress for low-strength mixtures, the toughness index is defined as the ratio of the area under the stress-strain curve up to a strain of $3 \varepsilon_{0}$ to the pre-peak area, in accordance with the method proposed by Mansur et al. (1999). The toughness indices of both matrixes and the fibre-containing mixtures thus calculated are listed in Table 4, and the effects of the steel fibre content on the toughness indices of the fibre-containing mixtures are shown in Figure 6(e). As can be seen, the toughness indices of higher strength mixtures are generally smaller than those of lowstrength mixtures, irrespective of the steel fibre content. This means that a mixture of higher strength is always less ductile than a mixture of lower strength. However, the inclusion of steel fibre makes this discrepancy become smaller. For instance, the toughness indices of mono-PVA fibre-reinforced M1, M2 and M3 mixtures are 2.07, 2.47 and 3·51, respectively. The presence of steel fibre with a volume fraction of $1.0 \%$ allows their toughness indices to increase to $2 \cdot 85,3.32$ and $3 \cdot 52$, respectively. In addition, such a behaviour implies that the effect of the steel fibre is strongly influenced by the matrix strength. For high-strength mixture (M1-), the inclusion of $0 \cdot 6,1 \cdot 0$ and $1.5 \%$ steel fibres leads to an improvement of 27,38 and $30 \%$ in toughness index, respectively. By contrast, the inclusion of $0.6,1.0$ and $1.5 \%$ steel fibres into a lowstrength mixture (M3-) leads to an improvement of $-9,0 \cdot 3$ and $4 \%$ in the toughness index, respectively. It can be seen that the improvement in toughness due to steel fibre decreases with decreasing matrix strength. When it comes to low-strength mixtures, the addition of steel fibre seems to make no obvious difference. From the toughness point of view, steel fibre may be more applicable to composites with a high-strength matrix.

\section{Analytical modelling of stress-strain curve of hybrid-fibre ECC in compression}

Reliable constitutive relations are desired to predict the complete stress-strain curve of concrete under uniaxial compression. In the past few decades, several efforts had been made to attain the analytical expressions particular to the stress-strain curve of ECC (Xu and Cai, 2010; Zhou et al., 2015). Based on comparisons between experimental results and predicted curves of four existing models, $\mathrm{Xu}$ and $\mathrm{Cai}$ (2010) proposed a simple analytical model to describe the complete stress-strain curve of materials similar to ECC, and good agreement resulted. However, in the model developed by Zhou et al. (2015), the pre-peak branch was described as the stress-strain curve, whereas the post-peak branch was described as the stress-deformation curve, considering the post-peak localisation characteristic of ECC. As hybrid-fibre ECC containing both PVA and steel fibres is concerned in this paper, an applicable model is needed to adequately describe its unique stress-strain behaviour.

All of the test results of ECC specimens with different waterto-binder ratios and steel fibre contents were employed to obtain an analytical model for hybrid-fibre ECC in compression. It is generally accepted that the pre- and post-peak portions of the stress-strain curve should be considered independently, as disparate characteristics exist between them (Van Mier et al., 1997). Accordingly, the stress-strain curve in this model is described as two parts: an ascending portion up to the peak stress and a subsequent descending portion. To describe the non-linear characteristics of the ascending portion, a polynomial expression usually applied to cementitious composites is used ( $\mathrm{Xu}$ and Cai, 2010; Zhou et al., 


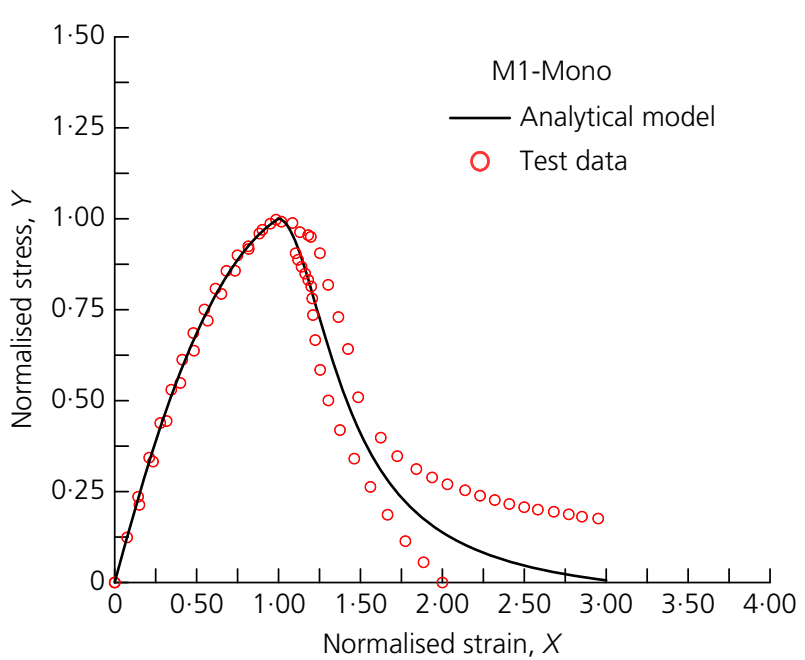

(a)

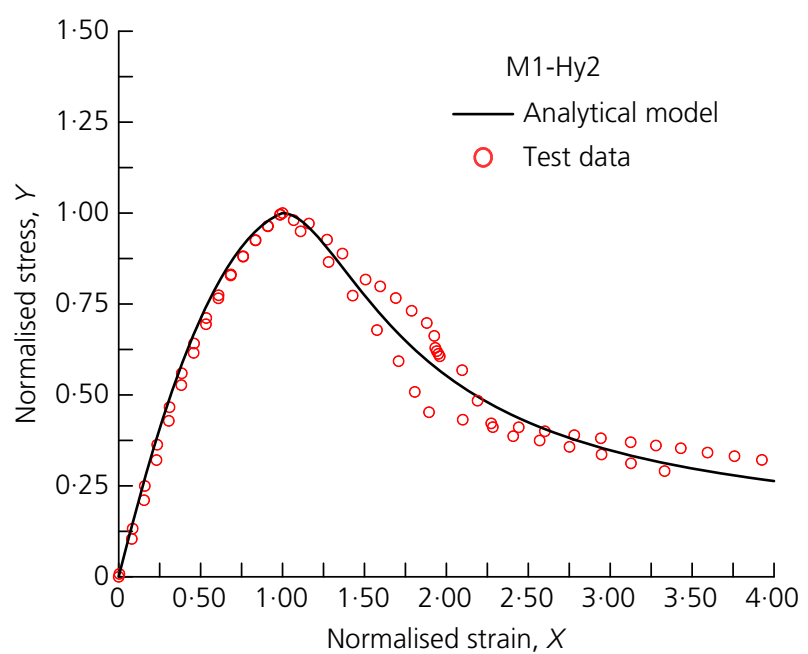

(c)

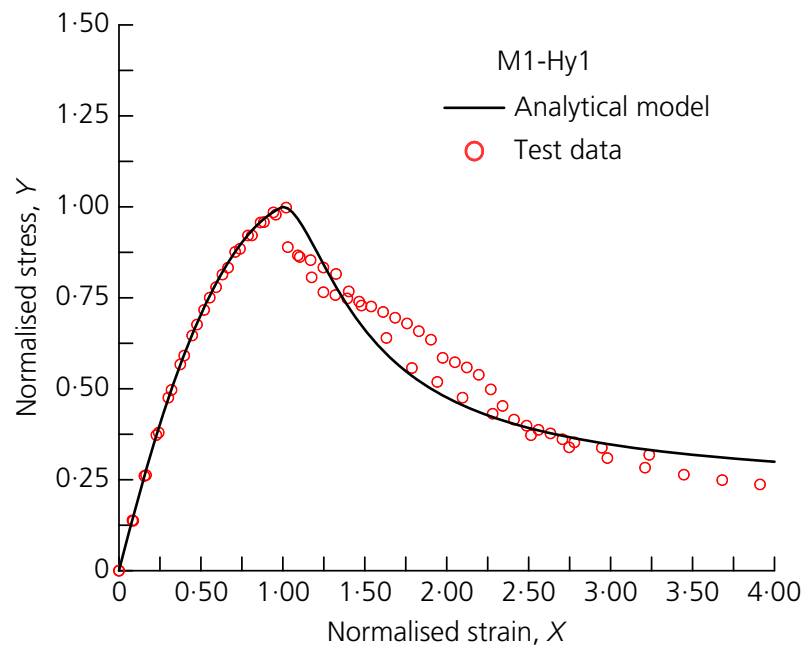

(b)

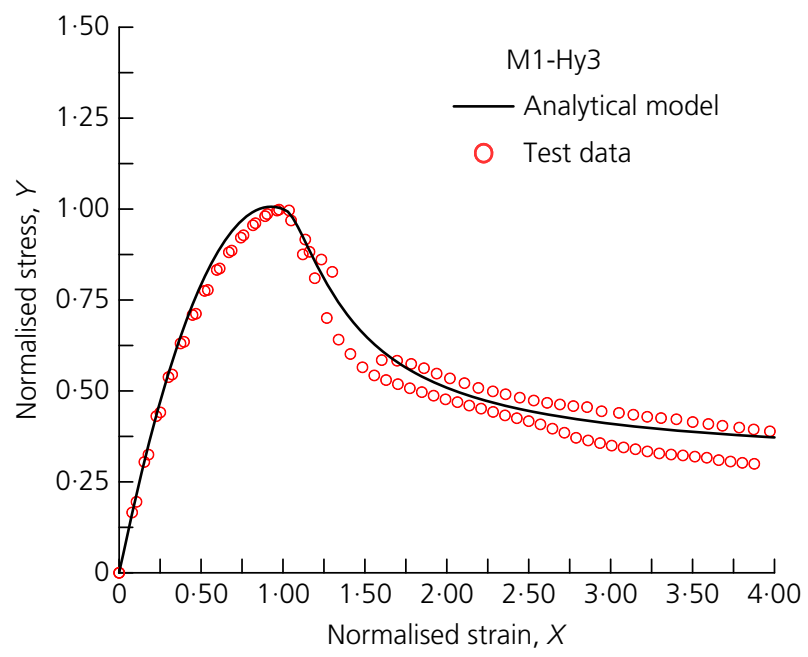

(d)

Figure 7. Comparison of normalised compressive stress-strain relations of hybrid-fibre-reinforced $\mathrm{M} 1$ obtained from proposed analytical model and test: (a) PVA1.7\%; (b) PVA1.7\%ST0.6\%; (c) PVA1.7\%ST1.0\%; (d) PVA1.7\%ST1.5\%

2015). Note that the normalised stress-strain curve passes through both the original point $(0,0)$ and the peak point $(1,1)$; the simple expression for the ascending portion is proposed as follows

$$
\text { 1. } \frac{\sigma}{f_{\mathrm{c}}}=\frac{\varepsilon}{\varepsilon_{0}}\left[\alpha\left(1-\frac{\varepsilon}{\varepsilon_{0}}\right)+1\right]
$$

where $\alpha$ is a material parameter that depends on the shape of the stress-strain curve. As discussed above, the ascending portion of the stress-strain curve behaves elastically from the original point up to the end point of the initial linear segment. Nevertheless, the initial linear characteristics are not concerned in the proposed analytical expression, for simplification. To determine $\alpha$, assume that the polynomial expression passes through the end point of the initial linear segment of the normalised experimental stress-strain curve, which means that the slope of the secant line at the proportional limit in the polynomial curve is equal to that of the initial linear segment of the normalised experimental stress-strain curve. Such an approximation would not result in much deviation because of the relatively small curvature at the initial stage of the polynomial curve. Thus, given a proportional limit, parameter $\alpha$ can be calculated based on this approximation relation. As mentioned above, the proportional limits of all the fibrecontaining mixtures averaged $0 \cdot 35$, with a small deviation of 0.022 . The effect of the matrix strength and the steel fibre dosage is then negligible, and the average value of 0.35 could be adopted as a unified proportional limit for all the fibre-containing mixtures. Hence, the equation derived for parameter $\alpha$ of each fibre-containing mixtures is allowed to be expressed simply by the parameters obtained above, and is 


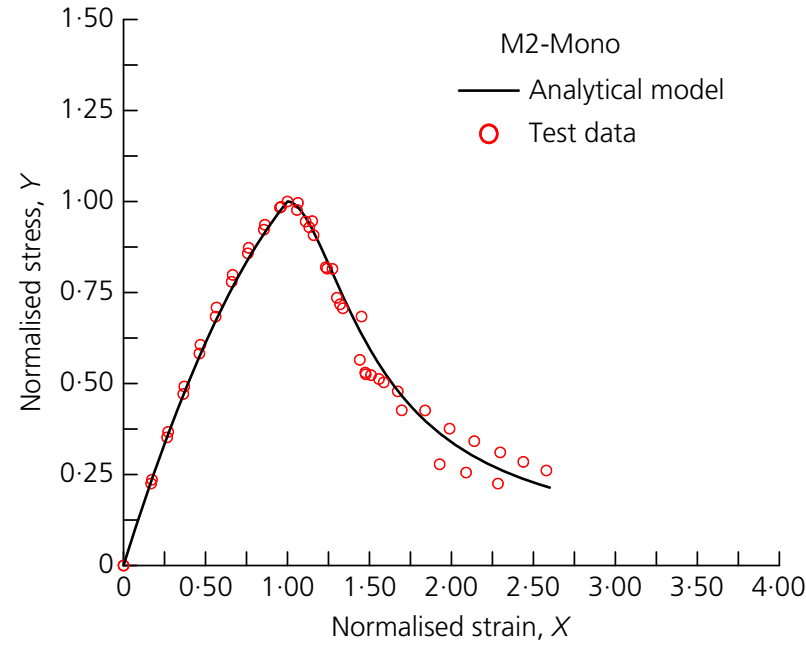

(a)

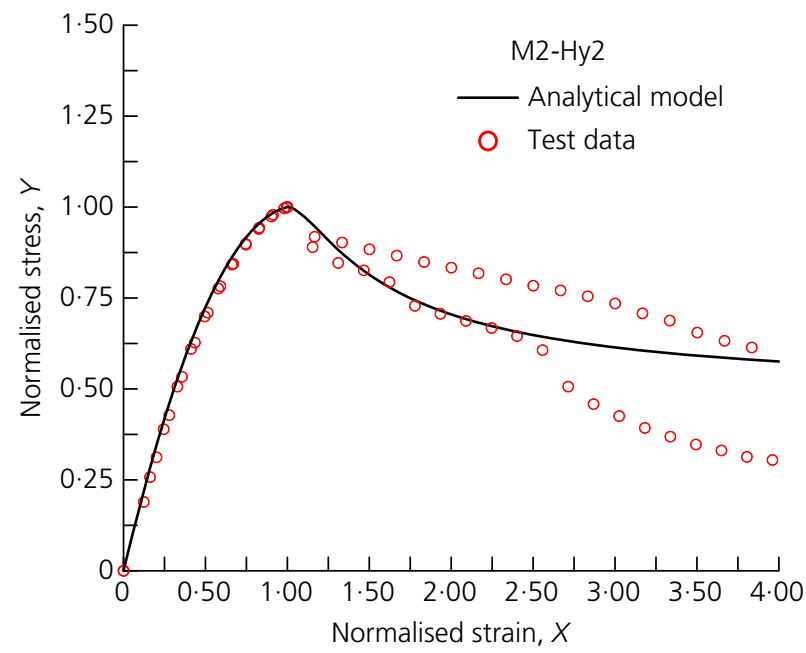

(c)

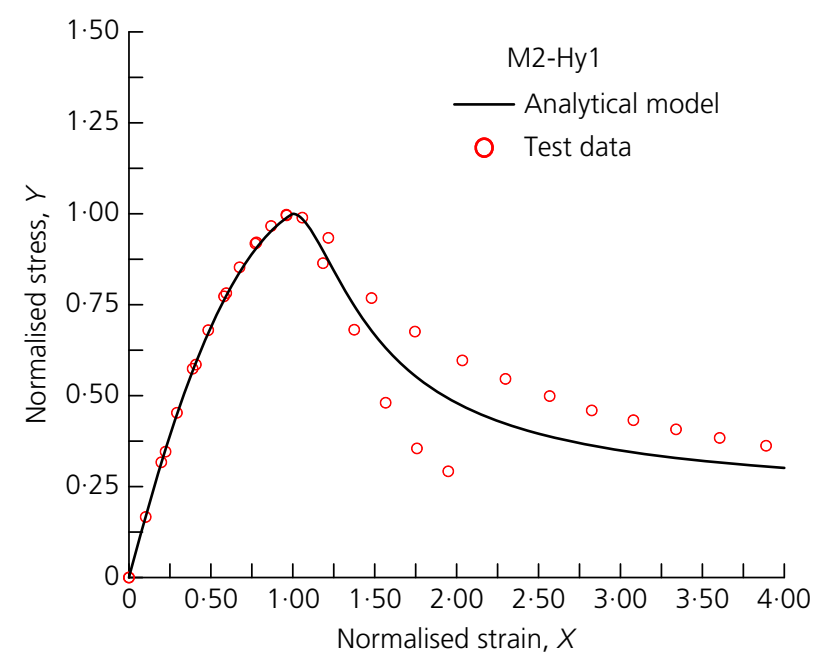

(b)

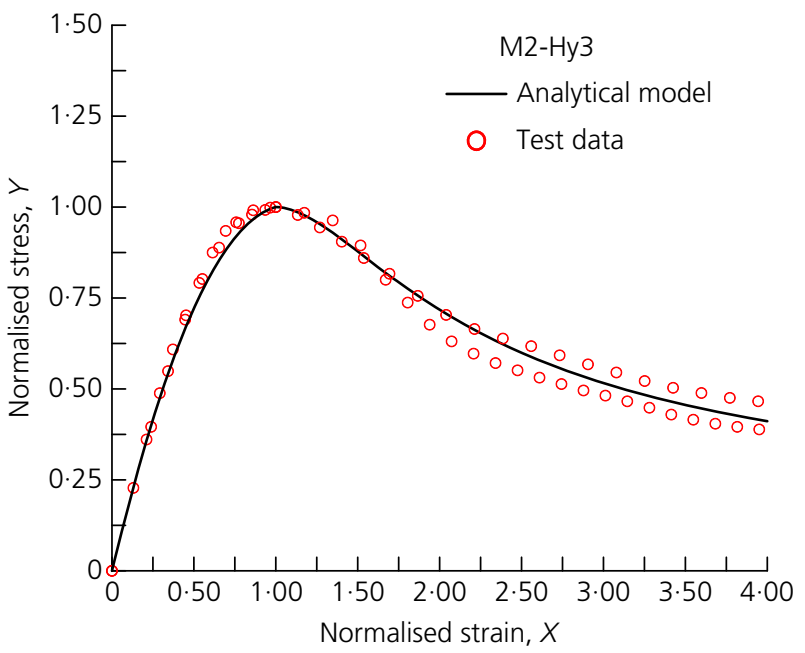

(d)

Figure 8. Comparison of normalised compressive stress-strain relations of hybrid-fibre-reinforced $\mathrm{M} 2$ obtained from proposed analytical model and test: (a) PVA1.7\%; (b) PVA1.7\%ST0.6\%; (c) PVA1.7\%ST1.0\%; (d) PVA $1.7 \%$ ST1.5\%

given as follows

2. $\alpha=\frac{E_{0} \varepsilon_{0} / f_{\mathrm{c}}-1}{1-\left(0 \cdot 35 f_{\mathrm{c}} / E_{0} \varepsilon_{0}\right)}$

To predict the descending portion of the curve, an analytical expression first developed by Fanella and Naaman (1985) for fibre-reinforced concrete was modified and examined in terms of its applicability to hybrid-fibre ECC. Considering the fact that the post-peak portion of the normalised stress-strain curve passes through the peak point $(1,1)$, the analytical expression proposed by Fanella and Naaman (1985) is simplified and represented by the following equation

4. $\sigma=f_{\mathrm{c}} \frac{A\left(\varepsilon / \varepsilon_{0}\right)+B\left(\varepsilon / \varepsilon_{0}\right)^{2}}{\left[\left(\varepsilon / \varepsilon_{0}\right)-1\right]^{2}+A\left(\varepsilon / \varepsilon_{0}\right)+B\left(\varepsilon / \varepsilon_{0}\right)^{2}}$ where both $A$ and $B$ are constants to be determined. With this expression, the descending portion could be predicted from test data at just two points of the post-peak stress-strain curve. In particular, the first point corresponds to the inflection point, while the second point corresponds to an arbitrary point taken at the tail end of the descending branch. The boundary condition and detailed determination method of the constants can be found in an earlier study performed by Fanella and Naaman (1985). Thus, the stress-strain curves for different hybrid-fibre ECCs can be predicted analytically following this method. The comparison of the normalised stress-strain curves of different mixtures obtained from the proposed analytical model and test data are presented in Figures 7-9. As these figures show, good agreement between the model prediction and the experimental results can be observed. The proposed analytical model can adequately describe both the ascending portion and the descending 


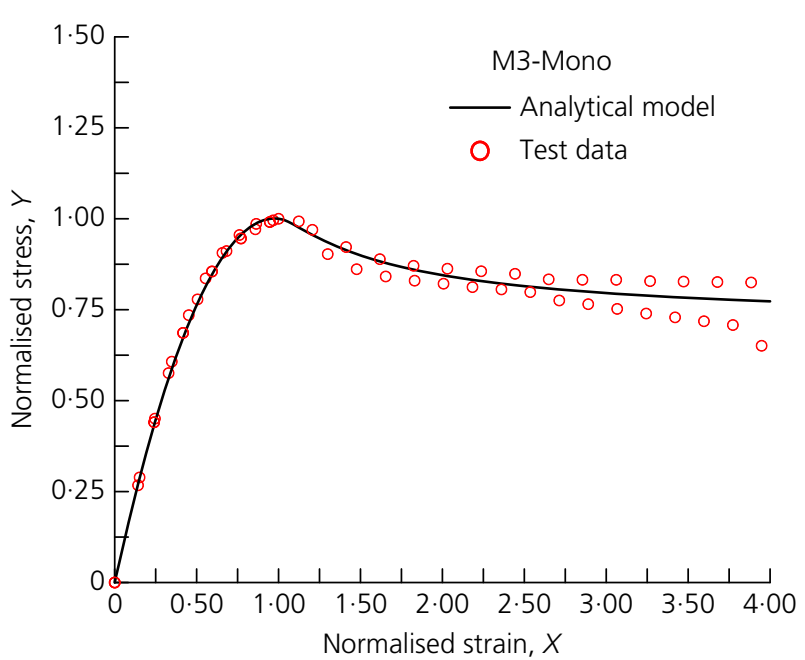

(a)

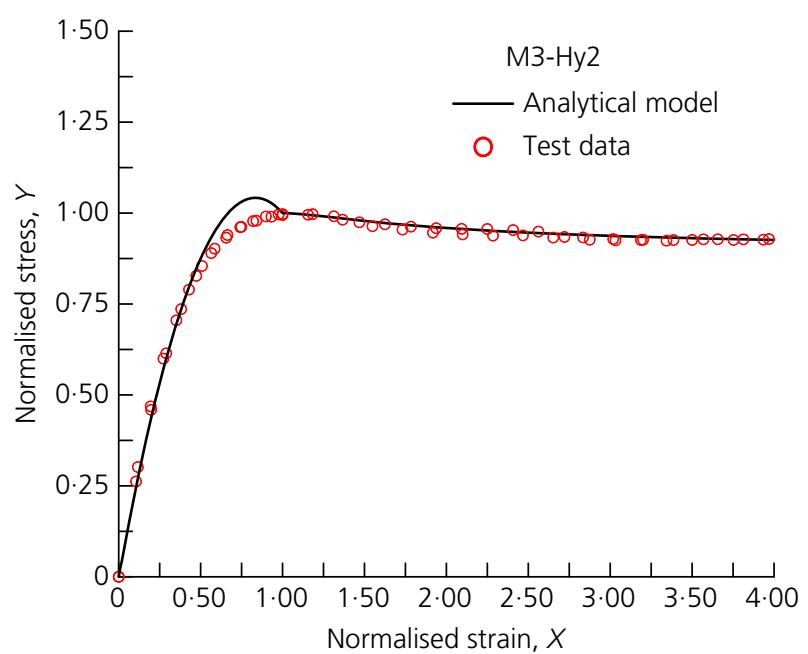

(c)

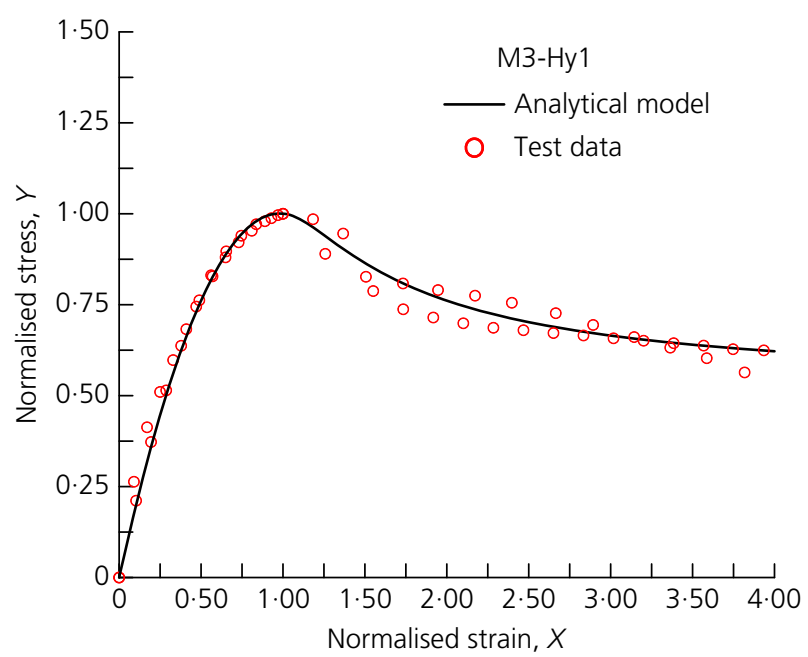

(b)

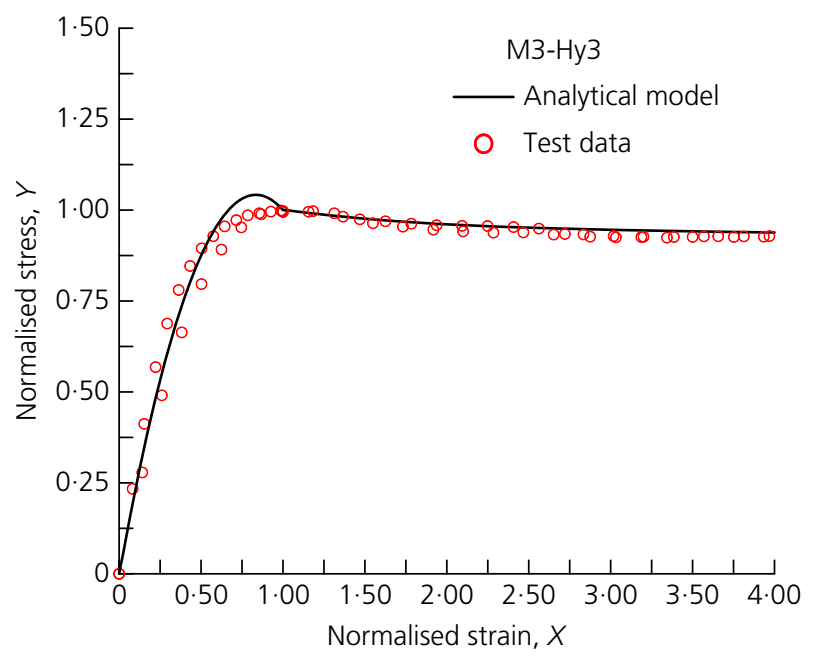

(d)

Figure 9. Comparison of normalised compressive stress-strain relations of hybrid-fibre-reinforced $\mathrm{M} 3$ obtained from proposed analytical model and test: (a) PVA1.7\%; (b) PVA1.7\%ST0.6\%; (c) PVA1.7\%ST1.0\%; (d) PVA1.7\%ST1.5\%

portion of the stress-strain curve for hybrid-fibre ECCs, serving as a first approximation for its practical design situations.

\section{Conclusion}

The stress-strain properties of PVA-steel hybrid-fibrereinforced ECC under uniaxial compression has been investigated in this research. Special attention has been paid to the impact of additional steel fibre content and matrix strength on the compressive performance. Thus, three matrix types with water-to-binder ratios of $0 \cdot 25,0 \cdot 35$ and 0.55 and three different steel fibre contents, with the PVA fibre content maintained at $1.7 \%$ in volume, were selected in the experimental programme. The experimental results indicated that the stress-strain behaviour of hybrid PVA-steel-fibre systems were improved by increasing the content of steel fibre, and this enhancement became more and more pronounced with decreasing waterto-binder ratio. For each compressive parameter, the impact of additional steel fibre was also strongly influenced by the matrix strength. As the matrix strength decreased, the positive effect of the steel fibre was reduced, and even transformed into a negative effect in the case of the low-strength M3 mixture. When considering both high strength and high toughness, a moderate amount of steel fibres was needed in the present hybrid system. Based on the experimental observations, a simple analytical model particular to the stress-strain curves of hybrid-fibre ECC was proposed, which gave satisfactory predictions of the complete stress-strain behaviour of the composites. It is believed that the model described in this research can be used as a first approximation for non-linear analysis of ECC structures. 


\section{Acknowledgements}

The authors gratefully acknowledge the support by Beijing Natural Science Foundation (grant no. 8184083), National Natural Science Foundation of China (grant no. 51622404), the Outstanding Young Talents of 'Ten Thousand People Plan' and the Yue Qi Distinguished Scholar Project of China University of Mining and Technology, Beijing.

\section{REFERENCES}

Banthia N, Majdzadeh F, Wu J and Bindiganavile V (2014) Fiber synergy in hybrid fiber reinforced concrete (HyFRC) in flexure and direct shear. Cement \& Concrete Composites 48(4): 91-97.

Fanella DA and Naaman AE (1985) Stress-strain properties of fiber reinforced mortar in compression. Journal of the American Concrete Institute 82(4): 475-483.

Li VC (1993) From micromechanics to structural engineering - the design of cementitious composites for civil engineering applications. Journal of Structural Mechanics and Earthquake Engineering, JSCE 10(2): 37-48.

Li VC (2002) Advances in ECC research. In Concrete: Material Science to Applications (Balagaru P, Naaman A and Wiess W (eds)). American Concrete Institute, Farmington Hills, MI, USA, ACI Special Publication SP 206-23, pp. 373-400.

Li VC, Mishra DK and Wu HC (1995) Matrix design for pseudo strain-hardening fiber reinforced cementitious composites. Materials and Structures 28(184): 586-595.

Li VC, Wu HC, Maalej M and Mishra DK (1996) Tensile behavior of cement-based composites with random discontinuous steel fibers. Journal of the American Ceramic Society 79(1): 74-78.

Maalej M, Quek S and Zhang J (2005) Behavior of hybrid-fiber engineered cementitious composites subjected to dynamic tensile loading and projectile impact. Journal of Materials in Civil Engineering ASCE 17(2): 143-152.
Maalej M, Quek ST, Ahmed SFU et al. (2012) Review of potential structural applications of hybrid fiber engineered cementitious composites. Construction and Building Materials 36: 216-227.

Mansur MA, Chin MS and Wee TH (1999) Stress-strain relationship of high-strength fiber concrete in compression. Journal of Materials in Civil Engineering, ASCE 11(1): 21-29.

Park SH, Kim JD, Ryu GS and Koh KT (2012) Tensile behavior of ultra high performance hybrid fiber reinforced concrete. Cement \& Concrete Composites 34(2): 172-184.

Van Mier JGM, Shah SP, Arnaud M et al. (1997) Strain-softening of concrete in uniaxial compression. Materials and Structures 30(4): 195-209.

Wang ZB, Zhang J, Wang JH and Shi ZJ (2015) Tensile performance of polyvinyl alcohol-steel hybrid fiber reinforced cementitious composite with impact of water to binder ratio. Journal of Composite Materials 49(18): 2169-2186.

Xu SL and Cai XR (2010) Experimental study and theoretical models on compressive properties of ultrahigh toughness cementitious composites. Journal of Materials in Civil Engineering ASCE 22(10): 1067-1077.

Yang EH, Yang Y and Li VC (2007) Use of high volumes of fly ash to improve ECC mechanical properties and material greenness. ACI Materials Journal 104(6): 303-311.

Zhang J, Gong CX, Guo ZL and Ju XC (2009a) Mechanical performance of low shrinkage engineered cementitious composite in tension and compression. Journal of Composite Materials 43(22): 2571-2584.

Zhang J, Gong CX, Zhang MH and Guo ZL (2009b) Engineered cementitious composite with characteristic of low drying shrinkage. Cement and Concrete Research 39(4): 303-312.

Zhang J, Wang ZB and Ju XC (2013) Application of ductile fiber reinforced cementitious composite in jointless concrete pavements. Composites: Part B 50: 224-231.

Zhou J, Pan J and Leung CKY (2015) Mechanical behavior of fiber reinforced engineered cementitious composites in uniaxial compression. Journal of Materials in Civil Engineering, ASCE 27(1): 1-10. 